\title{
FUZZY AHP GROUP DECISION ANALYSIS AND ITS APPLICATION FOR THE EVALUATION OF ENERGY SOURCES
}

\author{
Oliver Meixner \\ Institute of Marketing and Innovation \\ University of Natural Resources and Applied Life Sciences \\ Vienna, Austria \\ E-mail: oliver.meixner@boku.ac.at
}

\begin{abstract}
The following study focuses on the evaluation of a multi criteria decision problem by use of fuzzy logic. We will demonstrate the methodological considerations concerning group decision and fuzziness on the basis of a specific problem: the search for energy alternatives and a proper evaluation of these alternatives (in comparison to existing ones). This issue will be of increasing importance within the next years and decades. We will show using a numerical example how the evaluation process could be improved by use of fuzzy logic and Saaty's analytic hierarchy process (Saaty, 1980), in order to come close to reality and human cognitive behavior.
\end{abstract}

Keywords: fuzzy logic, fuzzy AHP, energy, group decision

\section{Introduction}

The main aim is to demonstrate an applicable way of improving evaluation tactics in complex decision problems (1) where there is a large number of decision makers (group decision in multi criteria decision making - MCDM), and (2) when there is a need to follow human behavior, where fuzziness comes closer to reality compared to classical evaluation processes using crisp data.

The first point refers to a general problem within decision making: which algorithm should be applied to aggregate evaluations of different decision makers? That is, how can we deal with inhomogeneous evaluations and runaway values? The second point refers to a scientific mainstream within decision making, the fuzzification of qualified MCDM methods going back to Zadeh's argumentation concerning fuzzy sets, first published in 1965 (Zadeh, 1965).

One widely used method which can handle both - group decisions and fuzziness - is the fuzzy analytic hierarchy process (AHP) - a further development of Saaty's widely used AHP technique (Saaty, 1980). Examples for the adequate application of the fuzzy AHP are, amongst others, the assessment of water management plans (Sredjevic and Medeiros, 2008); critical decisions in new product development (Büyüközkam and Feyziog̃lu, 2004); flexible manufacturing systems (Chutima and Suwanfuji 1998) and safety management in production (Dağdeviren and Yüksel, 2008); selection of enterprise resource planning systems (Cebeci, 2009); evaluation of success factors in e-commerce (Kong and Liu, 2005); personnel selection (Güngör et al., 2009); and weapon selection (Dağdeviren et al., 2009).

\section{The energy crisis and the need for a change in global energy strategies}

More specific contributions of fuzzy AHP can be found concerning the evaluation of energy sources. Jaber et al. (2008) delivered a contribution with a main focus on energy sources for space heating, containing a comparison of fuzzy sets analysis and AHP. Georgilakis and Katsigiannes (2009) deliver a published cost-benefit analysis of small autonomous power systems and Garciá et al. (1998) a feasibility study of alternative energy sources with main emphasis on greenhouse heating. However, we did not find an application of the fuzzy AHP with respect to energy with a more macroeconomic focus. This will become of growing importance as the global energy demand continues to increase dramatically (because of growing global population, the economic rise of China and India, amongst others) and as the extraction of fossil energy sources decline. Confirming the "BP Statistical Review of World Energy 2008" the 
global demand for electricity rocketed from about 5000 terawatt hours (TWh) per year in 1970 to about $20000 \mathrm{TWh}$ in 2007, 54\% of it consumed within OECD countries and 38\% in emerging nations (EME); the latter is the result of a doubling of the relative share from emerging nations within only 10 years (BP, 2008).

Confirming the so-called peak oil theory, fossil energy sources will be available for the next 35 years (if we follow the arguments of Kenneth Deffeyes, a well known expert concerning peak oil theory), 80 years confirming the International Energy Agency IEA, or 65 years confirming German experts (Stieler, 2006). After this period of time, our oil-based society will have to exploit alternative energy sources. One core advice of all experts is to establish a much more efficient use of energy to cope with this problem. However, increasing efficiency alone will not be sufficient; we will additionally need to search for alternative energy sources. It is a condition sine qua non to think about alternative and sustainable ways of producing energy. There are alternatives available, e.g. wind and solar energy for the purpose of a sustainable production of electricity. Wind energy produced a level greater than 121 gigawatt $(\mathrm{GW})$ in 2008, up from $7.5 \mathrm{GW}$ in 1997. It is anticipated that growth will continue over the next years, and by 2010 we should be able to produce $190 \mathrm{GW}$ with windmills (WWEA, 2009). According to the German governmental organization AGEE-Stat (BMU, 2009, 3), 9.7\% of the total German energy demand and $14.8 \%$ of the required electricity was produced through renewable resources. Currently, the most important renewable energy source is biomass followed by hydropower and wind. Concerning solar energy, in 2008 , only $0.16 \%$ of the total energy demand of Germany was produced through solar panels. However, the rate of growth in solar is huge with an increase of $29 \%$ from 2007 to 2008 . According to Solarbuzz LLC (a solar energy research and consultancy institute) global solar photovoltaic installations reached an all time high of $5.95 \mathrm{GW}$ in 2008, mainly installed in Germany and Spain (www.solaruzz.com). Furthermore, from a global perspective, in selected regions with adequate climatic conditions, solar energy could become one of the most important energy sources of the future.

Therefore, we will definitely have to evaluate alternative future pathways in our energy policy (e.g., concerning subsidies), which brings us back to the topic of this study. We have to find a solution for the following question. Which of the available alternatives should be promoted and subsidized more or less in the future, in order to enlarge the proportion of alternative energy sources within energy production and to bridge the prospective energy gap? The following presented numerical example should be considered an innovative way of evaluating different energy sources, taking into account that we discuss a future status which is, of course, connected with uncertainty. Therefore (and because of human psychology), it seems to be advisable to consider probabilities and fuzziness, which is the main reason for the implementation of the fuzzy AHP instead of the classical usage of the AHP (with crisp numbers) or other MCDM methods.

\section{A simplified decision model for the evaluation of energy sources}

To evaluate different energy sources we developed a simplified model. Obviously, the simplification reduces the practicability of the decision hierarchy. As mentioned above, to gain provisions concerning energy policy was not the main focus of this study. The focus was to demonstrate the principal feasibility of the fuzzy AHP in combination with a large number of group evaluations. To widen the applicability of the model, it would therefore be necessary to develop an improved approach. We will discuss this point later. For our purpose, a simple hierarchy containing only five criteria was deemed to be appropriate. The decision makers (see below) were asked to evaluate the importance of the hierarchy elements on the basis of the criteria

1. Cost (Co): price of a certain energy source, estimated as Euros per kWh (production cost of electricity)

2. Availability (Av) of an energy source: for some energy sources (like wind or solar energy) we have to consider reduced availability depending on climatic and geographic conditions. Other energy sources are more or less available continuously (like coal or natural gas).

3. Climate $(\mathrm{Cl})$ : environmental impacts of energy sources operationalized via $\mathrm{CO}_{2}$-equivalents per $\mathrm{kWh}$ 
4. Degree of dependency (De): dependency of a nation on foreign deliverers; via this criterion we tried to include the possible lack of different raw materials within a country, which are necessary for energy production, e.g. crude oil, natural gas or coal.

5. Utilizability (Ut): refers to the fields of application of a specific energy source; mainly connected with the question of centralized vs. decentralized energy production.

For the estimation of the importance of these criteria we used the fuzzy AHP. Let $\tilde{A}$ represent a fuzzified reciprocal $\mathrm{n} \cdot \mathrm{n}$-judgment matrix containing all pairwise comparisons $\tilde{a}_{i j}$ between elements $i$ and $j$ for all $i, j$ $\in\{1,2, \ldots, n\}$

$$
\tilde{A}=\left[\begin{array}{cccc}
(1,1,1) & \tilde{a}_{12} & \cdots & \tilde{a}_{1 n} \\
\tilde{a}_{21} & (1,1,1) & \cdots & \tilde{a}_{2 n} \\
\vdots & \vdots & \ddots & \vdots \\
\tilde{a}_{n 1} & \tilde{a}_{n 2} & \cdots & (1,1,1)
\end{array}\right]
$$

where $\tilde{a}_{j i}=\tilde{a}_{i j}^{-1}$ and all $\tilde{a}_{i j}$ are triangular fuzzy numbers $\tilde{a}_{i j}=\left(l_{i j}, m_{i j}, u_{i j}\right)$ with $l_{i j}$ the lower and $u_{i j}$ the upper limit and $m_{i j}$ is the point where the membership function $\mu(\mathrm{x})=1$. The membership function $\mu(\mathrm{x})$ of the triangular fuzzy number may therefore be described as (Chang, 1996, 650):

$\mu(x)=\left\{\begin{array}{cl}\frac{x-l}{m-l}, & x \in[l, m], \\ \frac{u-x}{u-m}, & x \in[m, u] \\ 0, & \text { otherwise }\end{array}\right.$

where $l_{i j} \leq m_{i j} \leq u_{i j}$. If $l_{i j}=m_{i j}=u_{i j}$ the fuzzy number gets a crisp number. In contrast to many other authors (e.g., Büyüközkam and Feyziog̃lu, 2004; Seçme et al., 2009), we did not fuzzify the crisp numbers quoted by each respondent by assuming fixed upper and lower limits. We left it up to the interviewees to quote the upper and lower limits, because we assume that they have different "confidence intervals" within which the true value of $a_{i j}$ might lie (where $a_{i j}$ represents any number within the interval $l_{i j} \leq u_{i j}$ ). In fact, we first asked the respondents to state a crisp value, i.e. $m_{i j}$. We used Saaty's 9-point scale ranging from 1 (=equal importance between element $i$ and $j$ ) to 9 (=absolute dominance of $i$ over $j$ ), and reciprocal values, respectively (Saaty, 1995, 73; for a general discussion on scales see Ji and Jiang, 2003, 897pp.). All values within the range of 1 to 9 and $1 / 9$ to 1 are possible; the respondents were not restricted to the integer data points 1,2 etc. and their reciprocals.

Following this, respondents could state an area below $\left(l_{i j}\right)$ or above $\left(u_{i j}\right)$, this value $\left(m_{i j}\right.$ can therefore $n o t$ be interpreted as the modal value like in Chang, 1996, 650). Even a shift from one side of the scale (e.g. 2) to the reciprocal side (e.g. 0.25) was possible; here again, decision makers were not restricted. As an example, the following figure represents evaluations of the elements "Cost" and "Dependency" of respondents \#96 and \#102, which clearly shows that different respondents generate - besides different setting point $m_{i j}$ - varying spans between $l_{i j}$ and $m_{i j}$ and between $m_{i j}$ and $u_{i j}$, respectively. 


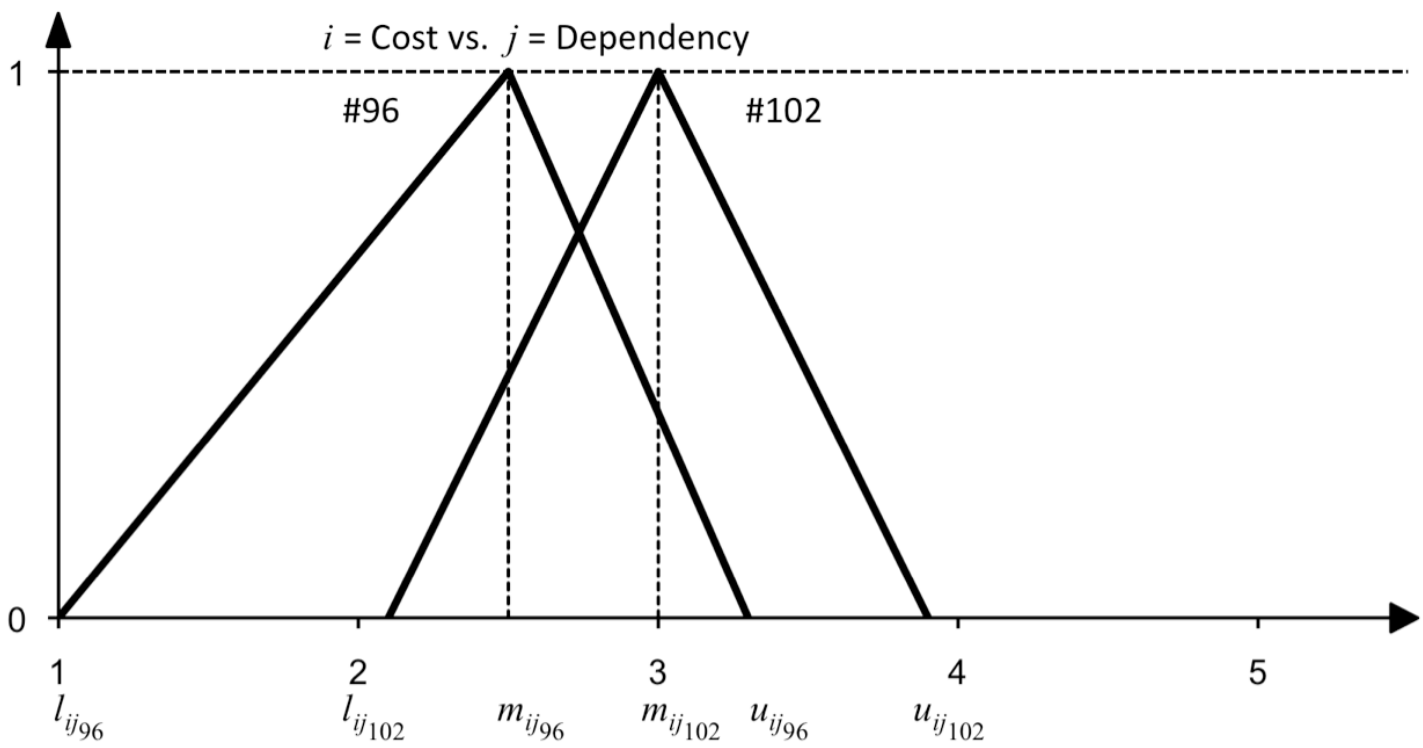

Fig. 1. Example of fuzzy evaluations of respondent \#96 and \#102, determining autonomously $l_{i j}, m_{i j}$ and $u_{i j}$, criteria "Cost" vs. "Dependency".

The assumption of triangular fuzzy numbers is of course a simplification, which can be found frequently in literature (e.g., Mikhailov, 2003, 368) and which facilitates fuzzy arithmetic calculations. It is possible to use the operation laws following Zadeh's extension principle via this simplification (Zadeh, 1965; see also, amongst others, Chang, 1996, 650; Büyüközkam and Feyziog̃lu, 2004, 44), which makes calculations much easier (or even possible). Assume that $\tilde{M}_{1}$ and $\tilde{M}_{2}$ are two triangular fuzzy numbers with $\tilde{M}_{1}=\left(l_{1}, m_{1}, u_{1}\right)$ and $\tilde{M}_{2}=\left(l_{2}, m_{2}, u_{2}\right)$. The basic operations are:

$$
\begin{aligned}
& \tilde{M}_{1} \oplus \tilde{M}_{2}=\left(l_{1}+l_{2}, m_{1}+m_{2}, u_{1}+u_{2}\right) \\
& \tilde{M}_{1} \otimes \tilde{M}_{2} \approx\left(l_{1} l_{2}, m_{1} m_{2}, u_{1} u_{2}\right) \\
& \tilde{M}_{1}^{-1} \approx\left(\frac{1}{u_{1}}, \frac{1}{m_{1}}, \frac{1}{l_{1}}\right)
\end{aligned}
$$

We will need these operation laws in order to be able to estimate priorities out of the fuzzy matrix $\tilde{A}$. Before that, we need to assure two points: (I) we have to evaluate consistency for each respondent, and (II) we have to find ways of aggregating the single pairwise comparisons (group decision). Point (I) will be discussed in the following section.

\section{Consistency analysis of individual evaluations}

The participants within this study were 114 Austrian students studying "Environment and Bio-Resources Management" at the University of Natural Resources and Applied Life Sciences Vienna. They may be considered informed decision makers with respect to the topic of the evaluation process (valuation of criteria to be able to estimate the ability of diverse energy sources, e.g., oil, gas, solar energy, etc. to cover the future energy demand). The data was collected in 2007; a re-collection was carried out in 2008 (about 40 cases) to review the significance of the findings in view of reliability. The following analysis only refers to the original sample of 114 participants. To estimate priorities out of a given pairwise comparison matrix, we followed the suggestion of Saaty $(2006,77 \mathrm{pp}$.) and used the Eigenvector method. 
To assure a certain quality level of a decision, we have to analyze the consistency of an evaluation. For this purpose, we calculated the consistency ratio (CR) confirming Saaty $(1995,81)$, which is defined as a ratio between the consistency of a given evaluation matrix (consistency index CI) and the consistency of a random matrix (for Saaty's scale using numerical judgments from 1/9, 1/8, .. 1, 2, .. 9, Saaty quotes for a 5.5-reciprocal matrix a random consistency $\mathrm{RC}$ of 1.11). The $\mathrm{CR}$ of a decision should not exceed a certain level, namely 0.1 for a matrix larger than 4 by 4 (Saaty, 1995, 81). Therefore, we decided to include only evaluations which fulfill the condition CR $\leq 0.1$. Confirming Saaty (1980) we can approximate $\mathrm{CR}$ via $\lambda_{\max }$ :

$$
C I=\frac{\lambda_{\max }-n}{n-1} \text { and } C R=\frac{C I}{R C} \leq 0.1
$$

To simplify the calculation of the CR, we used the crisp value $m_{i j}$. If the CR exceeded the tolerable level of 0.1 , we excluded the pairwise comparison matrix of this respondent for further analysis, because this could affect the overall results negatively. In this respect, it has to be mentioned, that data collection was done by a simple, spreadsheet-based computer program with graphical bars. The evaluators received feedback about the priorities and the consistency of their pairwise comparisons immediately and had therefore the possibility to redo them. However, although we provided this interactive platform for the evaluation process, we had to realize that many evaluations were quite inconsistent. In total we received 114 evaluations. Following the first knock out-criterion $\mathrm{CR} \leq 0.1$ we had to exclude 39 cases because of a lack of consistency; leaving 75 evaluations remaining in the sample for further analysis. This would definitely not be satisfying if we were intending to deduce future strategies concerning energy policy. However, for the purpose of our study, a reduced consistency within some of the sample is negligible, as far as a sufficiently high number of respondents still remain in the sample.

\section{Aggregation of group decisions}

The analytical step (II) mentioned above refers to the aggregation of the group evaluations. Fuzzy pairwise comparisons can be combined by use of the following algorithm (Büyüközkam and Feyziog̃lu, 2004, 39; Chang et al., 2009, 7365):

$$
l_{i j}=\min \left(l_{i j k}\right), m_{i j}=\left(\prod_{k=1}^{K} m_{i j k}\right)^{1 / K}, u_{i j}=\max \left(u_{i j k}\right)
$$

where $\left(l_{i j k}, m_{i j k}, u_{i j k}\right)$ is the fuzzy evaluation of sample members $k(k=1,2, \ldots, K)$. However, min and max operations are not appropriate if the sample has a wide range of upper and lower bandwidths, in other words, if evaluations are inhomogeneous. We have to consider that if only one or few decision makers deliver extreme $l_{i j k}$ and/or $u_{i j k}$ the whole span of fuzzy numbers $\left(l_{i j}, m_{i j}, u_{i j}\right)$ gets huge. Due to the required number of multiplication and addition operations, the aggregated fuzzy weights can even exceed the $0-1$ borders or become irrational (Mikhailov, 2003, 367), which is of course, unsatisfactory. Therefore, we decided to use the geometric mean also for $l_{i j}$ and $u_{i j}$ which delivers satisfying fuzzy group weightings. Geometric mean operations are commonly used within the application of the AHP for aggregating group decisions (Davis, 1994, 52):

$$
l_{i j}=\left(\prod_{k=1}^{K} l_{i j k}\right)^{1 / K}, m_{i j}=\left(\prod_{k=1}^{K} m_{i j k}\right)^{1 / K}, u_{i j}=\left(\prod_{k=1}^{K} u_{i j k}\right)^{1 / K}
$$


This is a rather new approach, which is of course connected to a certain information loss. However, this loss should be tolerable, especially if we take into account the main advantage of this approach. Isolated runaway values will not affect the results dramatically, unlike min-max operations. In our case, we get the following aggregated fuzzy pairwise comparisons $\left(l_{i j}, m_{i j}, u_{i j}\right)$ :

Table 1. Pairwise comparison matrix of all evaluations $(\mathrm{CR} \leq 0.1, \mathrm{n}=75)$

\begin{tabular}{llllll}
\hline & Co & Av & Cl & De & Ut \\
\hline Cost (Co) & $(1,1,1)$ & $(0.38,0.58,1.19)$ & $(0.32,0.45,0.77)$ & $(1.07,1.71,2.79)$ & $(0.62,0.88,1.32)$ \\
Availabiltity (Av) & $(0.84,1.74,2.64)$ & $(1,1,1)$ & $(0.44,0.74,1.23)$ & $(1.72,2.35,3.35)$ & $(0.86,1.32,2.00)$ \\
Climate (Cl) & $(1.31,2.22,3.10)$ & $(0.80,1.36,2.27)$ & $(1,1,1)$ & $(1.89,2.83,3.77)$ & $(1.20,1.80,2.64)$ \\
Dependency (De) & $(0.36,0.58,0.93)$ & $(0.30,0.43,0.58)$ & $(0.26,0.35,0.53)$ & $(1,1,1)$ & $(0.42,0.55,0.82)$ \\
Utilizability (Ut) & $(0.76,1.14,1.62)$ & $(0.50,0.76,1.17)$ & $(0.38,0.56,0.83)$ & $(1.22,1.80,2.41)$ & $(1,1,1)$ \\
\hline
\end{tabular}

\section{Approximation of fuzzy priorities}

Based on the combined results of all decision makers $(n=75)$, we estimated the priorities using two methods: (a) we calculated the results based on the so-called synthetic extent analysis by Chang (1996), which is only possible when the evaluations are rather consistent (using a simple arithmetic mean algorithm; Mikhailov, 2003, 367). Our raw data fulfilled this criterion (inconsistent evaluations were eliminated). Therefore, an approximation using Chang's method should deliver satisfying results. Chang's method is based on the assumption, that the degree of possibility of a certain triangular fuzzy number $\tilde{M}_{2} \geq \tilde{M}_{1}$ can be expressed by equation (10).

$V\left(\tilde{M}_{2} \geq \tilde{M}_{1}\right)=\operatorname{hgt}\left(\tilde{M}_{1} \cap \tilde{M}_{2}\right)= \begin{cases}1, & \text { if } m_{2} \geq m_{1} \\ 0, & \text { if } l_{1} \geq l_{2} \\ \frac{l_{1}-u_{2}}{\left(m_{2}-u_{2}\right)-\left(m_{1}-l_{1}\right)}, & \text { otherwise }\end{cases}$

Confirming this method, it is necessary to compare both, $V\left(\tilde{M}_{2} \geq \tilde{M}_{1}\right)$ and $V\left(\tilde{M}_{1} \geq \tilde{M}_{2}\right)$.

Defuzzification is then possible by searching for the minimum of all the $k$ convex numbers (Chang, 1996, 651) by $\min V\left(\tilde{M} \geq \tilde{M}_{i}\right), i=1,2, \ldots, k$. With respect to the weightings within the fuzzy AHP, we have to calculate the fuzzy synthetic extent, which is defined as:

$\tilde{S}_{i}=\sum_{j=1}^{m} \tilde{M}_{g_{i}}^{j} \otimes\left[\sum_{i=1}^{n} \sum_{j=1}^{m} \tilde{M}_{g_{i}}^{j}\right]^{-1}$

where $g_{\mathrm{i}}$ are the goals of the decision hierarchy and $\tilde{M}_{g_{i}}^{j}$ represent the triangular fuzzy numbers of the decision matrix with $\mathrm{i}=1,2, \ldots, n$ and $\mathrm{j}=1,2, \ldots, m$ and $n$ objects and $m$ goals (in contrast to Chang, 1996, we continue using the fuzzy notation for $\tilde{S}_{i}$, as it is still a fuzzy number). Through normalization, we can estimate the non-fuzzy weight vector $\mathrm{W}$, which is defined by:

$W=\left(\min V\left(\tilde{S}_{1} \geq \tilde{S}_{k}\right), \min V\left(\tilde{S}_{2} \geq \tilde{S}_{k}\right), \ldots, \min V\left(\tilde{S}_{n} \geq \tilde{S}_{k}\right)\right)^{\mathrm{T}}$ 
(b) In addition, we calculated the priorities via the geometric means method of Buckley (1985; Buckley et al., 2001, 50; see also Cebeci, 2009, 8907) where:

$$
\tilde{r}_{i}=\left(\prod_{j=1}^{n} \tilde{p}_{i j}\right)^{1 / n}
$$

and

$$
\tilde{w}_{i}=\tilde{r}_{i} \otimes\left(\sum_{i=1}^{n} \tilde{r}_{i}\right)^{-1}, i=1,2, \ldots, n
$$

The fuzzy number $\tilde{w}_{i}$ has to be defuzzified. Confirming Opricovic and Tzeng $(2003,641)$ and Chang and Wang (2009) we can use a simple centroid method for this purpose (Chang and Wang, name the nonfuzzy weights as the "best nonfuzzy performance (BNP) values" (Chang and Wang, 2009, 361)):

$$
w_{i}=l_{i}+\frac{\left(m_{i}-l_{i}\right)+\left(u_{i}-l_{i}\right)}{3} \text { or } w_{i}=\frac{l_{i}+m_{i}+u_{i}}{3}, i=1,2, \ldots, n
$$

Further defuzzification methods would be possible, like the CFCS method proposed by Opricovic and Tzeng $(2003,643)$, the fuzzy mathematical programming method proposed by Mikhailov (2004) or the fuzzification of Saaty's method (the Lamda-Max method) proposed by Csutora and Buckley (2001; see also Buckley et al. 2001). We abstained from using other methods at this point of the study; this could be a matter for further research.

\section{Results}

Out of the pairwise comparison matrix in Table 1 we can now estimate the weightings based on the methods (a) and (b) mentioned above.

(a) Chang's method: After calculating $\tilde{S}_{i}$ we can estimate the non-fuzzy priority vector $W$ using equation (11):

$$
\begin{aligned}
& \tilde{S}_{C o}=(0.08,0.16,0.34), \tilde{S}_{A v}=(0.12,0.25,0.49), \tilde{S}_{C l}=(0.15,0.32,0.62) \\
& \tilde{S}_{D e}=(0.06,0.10,0.19), \tilde{S}_{U t}=(0.09,0.18,0.34)
\end{aligned}
$$

Using these Vectors we get:

$$
\begin{aligned}
& V\left(\tilde{S}_{C o} \geq \tilde{S}_{A v}\right)=0.72, V\left(\tilde{S}_{C o} \geq \tilde{S}_{C l}\right)=0.55, V\left(\tilde{S}_{C o} \geq \tilde{S}_{D e}\right)=1.00, V\left(\tilde{S}_{C o} \geq \tilde{S}_{U t}\right)=0.92, \\
& V\left(\tilde{S}_{A v} \geq \tilde{S}_{C o}\right)=1.00, V\left(\tilde{S}_{A v} \geq \tilde{S}_{C l}\right)=0.83, V\left(\tilde{S}_{A v} \geq \tilde{S}_{D e}\right)=1.00, V\left(\tilde{S}_{A v} \geq \tilde{S}_{U t}\right)=1.00 \\
& V\left(\tilde{S}_{C l} \geq \tilde{S}_{C o}\right)=1.00, V\left(\tilde{S}_{C l} \geq \tilde{S}_{A v}\right)=1.00, V\left(\tilde{S}_{C l} \geq \tilde{S}_{D e}\right)=1.00, V\left(\tilde{S}_{C l} \geq \tilde{S}_{U t}\right)=1.00 \\
& V\left(\tilde{S}_{D e} \geq \tilde{S}_{C o}\right)=0.64, V\left(\tilde{S}_{D e} \geq \tilde{S}_{A v}\right)=0.32, V\left(\tilde{S}_{D e} \geq \tilde{S}_{C l}\right)=0.14, V\left(\tilde{S}_{D e} \geq \tilde{S}_{U t}\right)=0.54 \\
& V\left(\tilde{S}_{U t} \geq \tilde{S}_{C o}\right)=1.00, V\left(\tilde{S}_{U t} \geq \tilde{S}_{A v}\right)=0.77, V\left(\tilde{S}_{U t} \geq \tilde{S}_{C l}\right)=0.58, V\left(\tilde{S}_{U t} \geq \tilde{S}_{D e}\right)=1.00
\end{aligned}
$$

Therefore, $W$ is approximated by minimizing and normalizing $V$. 
We get $W=(0.18,0.27,0.32,0.05,0.19)^{\mathrm{T}}$.

(b) Geometric mean: Using equation (13), we can approximate $\tilde{w}_{i}$ and get $\tilde{w}_{C o}=(0.08,0.15,0.34), \quad \tilde{w}_{A v}=(0.11,0.24,0.49), \quad \tilde{w}_{C l}=(0.16,0.32,0.62), \quad \tilde{w}_{D e}=(0.05,0.10,0.20)$, and $\tilde{w}_{U t}=(0.09,0.18,0.34)$.

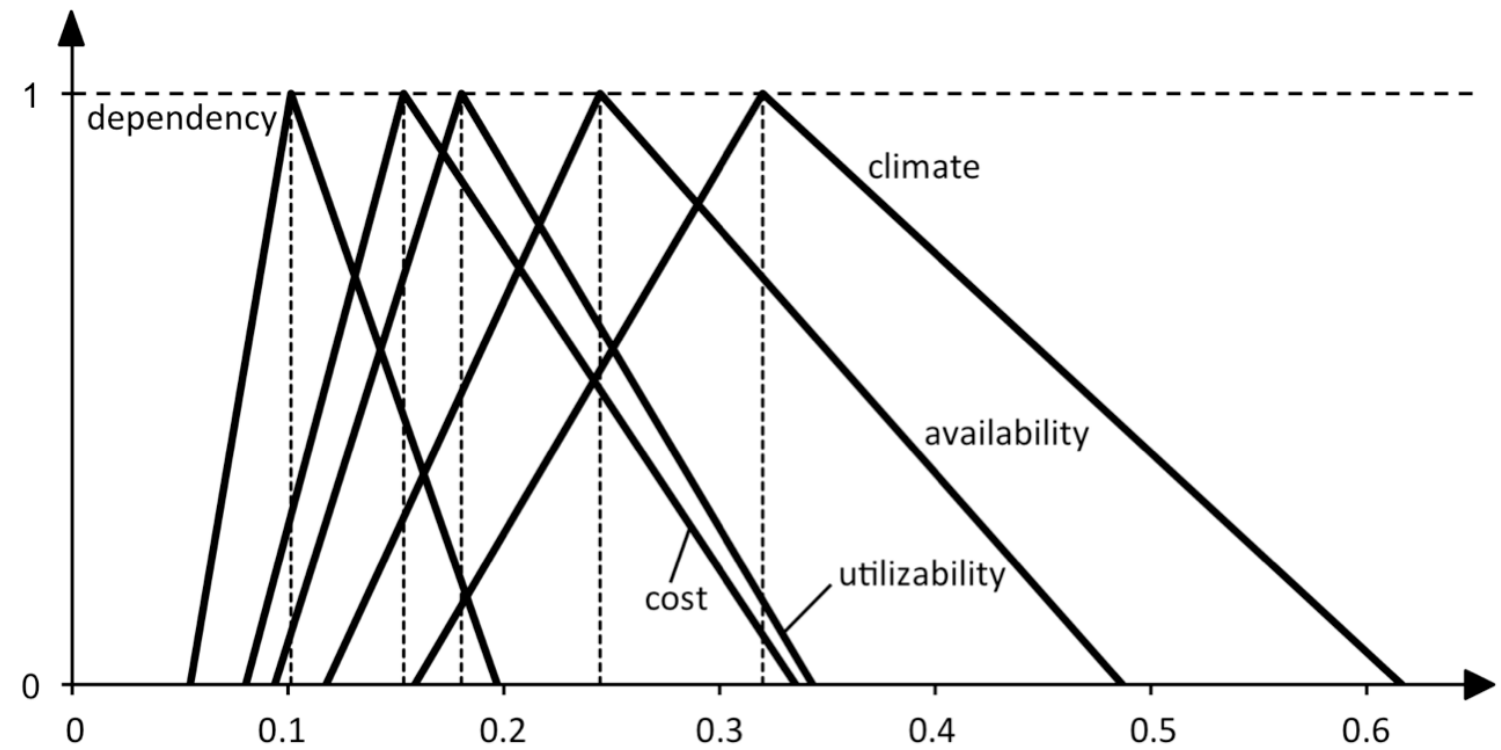

Fig. 2. Fuzzy weights $\tilde{w}_{i}$, geometric means estimation

Figure 2 shows the fuzzy weights of $\tilde{w}_{i}$ based on the geometric means calculations. As we can see, $l_{i}$ and $u_{i}$ become quite large for all criteria except "dependency". As mentioned above, this is a typical result of fuzzy AHP. Due to fuzzy calculations and the required number of multiplications and addition operations, there is usually a wide span between values $l_{i}$ and $u_{i}$ (Mikhailov, 2003, 367; see also Eickemeier and Rommelfanger, 2001, 142). After defuzzification using equation (15) (centroid method) we get $w_{i}=(0.16,0.24,0.32,0.10,0.17)$.

Table 2. Aggregated evaluation of criteria.
(a) Chang's method
(b) Geometric means approximation

\begin{tabular}{lllll} 
& $\tilde{S}_{i}$ & $W$ & $\tilde{w}_{i}$ & $w_{\mathrm{i}}$ \\
\hline Cost & $(0.08,0.16,0.34)$ & 0.18 & $(0.08,0.15,0.34)$ & 0.16 \\
Availability & $(0.12,0.25,0.49)$ & 0.27 & $(0.12,0.24,0.49)$ & 0.24 \\
Climate & $(0.15,0.32,0.62)$ & 0.32 & $(0.16,0.32,0.62)$ & 0.31 \\
Dependency & $(0.06,0.10,0.19)$ & 0.05 & $(0.05,0.10,0.20)$ & 0.10 \\
Utilizability & $(0.09,0.18,0.34)$ & 0.19 & $(0.09,0.18,0.34)$ & 0.18 \\
\hline
\end{tabular}

Table 2 summarizes the results of both estimation methods (a) and (b), containing fuzzy synthetic extents $\tilde{S}_{i}$ and $W$ for Chang's method and fuzzy weights $\tilde{w}_{i}$ and $w_{\mathrm{i}}$ for geometric means approximation. 


\section{Discussion of criteria weighting}

Both estimation methods deliver comparable, satisfying results. By use of Chang's method, there is a slight shift from less important to more important criteria. If we want to put emphasis on the most important criteria then this could be of advantage. If for example, one criterion is not important at all, it would get a weight of 0 (it is in fact negligible), which seems to be a good representation of reality. Criteria which are not useful to be considered within a decision hierarchy can now be eliminated by use of Chang's algorithm. However, we have to consider that this estimation procedure is only valid if we dispose of consistent evaluations; as we excluded inconsistent evaluations within this sample, this condition was fulfilled. Further: For the aggregated pairwise comparison matrix we approximated CR on the basis of $m_{i j}$ and got $\mathrm{CR} \approx 0.003$; the matrix can therefore be considered to be consistent.

The estimations based on geometric means deliver comparable results. Only the criterion "Dependency" has a much lower crisp weight value compared to Chang's method. This could be a disadvantage, and in fact many respondents seem to consider the criterion "Dependency" as unnecessary for the evaluation of energy sources. The interviewees had the possibility to tick a marker within the questionnaire if a criterion is unimportant in their opinion; this had no consequences for the further evaluation process. One fourth of all respondents classified the criterion as "not important" - the highest share by far of all criteria within the hierarchy. However, from this empirical study it cannot be concluded that one method is more preferable compared to another. The main result is that both estimation methods deliver satisfying results and both seem therefore to be applicable (assuming that inconsistent weightings are eliminated).

Concerning the aggregation algorithm of a group decision we might conclude the following: The use of the geometric mean instead of a minimum and maximum operation seems to be of advantage when aggregating fuzzy numbers. Otherwise the calculated weights tend to exceed a tolerable range because of isolated runaway values. Of course, the use of the geometric mean is no guarantee that it is always possible to calculate applicable fuzzy weightings. Assuming a big group of decision makers, single extreme values shall not be harmful if the majority of them evaluates homogeneously, at least to a certain degree. If a sample is too heterogeneous it could be advisable to further split it into subgroups and compare and discuss the different results of these groups. However, for the purpose of this study, a splitting was not necessary. The analysis associated with clustering and homogeneity will be subject to future research. Furthermore, a comparison with other aggregation methods as well as prioritization algorithms like in Opricovic and Tzeng (2003) could be of advantage; these too are left for future research.

\section{Evaluation of selected alternatives}

Of course, a more sophisticated model would be appropriate to evaluate energy sources to cope with our future energy demand. This model could then be taken to evaluate the importance of the criteria within the model to be evaluated by national and international experts - as was done with the group members within this empirical example. The aggregation and prioritization procedure could be the same as it was done herein. In the end, we would generate a decision hierarchy by which it is possible to evaluate different alternatives (energy sources). For this last step we should use quantitative data if applicable. The following results give an indication about the final estimation of an alternative ranking based on the priorities calculated above (we will use the results of the geometric means estimation). For this purpose, we take the quantitative data in Table 3 , on the basis of which we evaluate three alternatives to produce electricity: photovoltaics, windmills, and coal fired power plants. Of course, it would be possible to acquire even more detailed information. This data (although imprecise) will be sufficient to show the principal feasibility of the ranking procedure. Here also, a more sophisticated accession would be mandatory if we wanted to deduct suggestions concerning energy sources. 
Table 3. Quantitative data for the evaluation of 3 selected alternatives.

\begin{tabular}{lrrrrr}
\hline & ${ }^{\mathrm{a}}$ Cost & ${ }^{\mathrm{b}}$ Availability & ${ }^{\mathrm{c}}$ Climate & ${ }^{\mathrm{d}}$ Dependency & ${ }^{\mathrm{e}}$ Utilizability \\
\hline Photovoltaics & 0.15 & 1897.7 & 101 & 1 & 1 \\
Windmills & 0.05 & 1111.2 & 24 & 1 & 1 \\
Coal fired power plants & 0.08 & 8750.0 & 1153 & 0 & 0
\end{tabular}

${ }^{a}$ Electricity production cost in EUR/kWh; forecast for the year 2030; source: BMU, 2004, 194

${ }^{\mathrm{b}}$ Availability in hours per year; long year average for a selected Austrian region, ZMAG (central Austrian meteorological agency); coal is supposed to be available the whole year

${ }^{c}$ Environmental impacts, emissions in $\mathrm{g} \mathrm{CO}_{2} / \mathrm{kWh}$; source: Technology Review, 7/2007, 86

${ }^{\mathrm{d}}$ Simplified assumption for a country with no significant resources/technological access (value 0 ) or available resources/access (1)

${ }^{\mathrm{e}}$ Simplification: decentralized energy production is possible (value 1); only centralized power plants are feasible $(0)$.

This data was normalized (see Table 5; for criteria "Cost" and "Climate" we use inverse data, as a higher amount is less preferable; see Table 4) and then combined with the relevant weight of each criterion. By multiplying these values with the crisp values $w_{i}=(0.16,0.24,0.31,0.10,0.18)$ from above, we approximate the aggregated, global weights for the three alternatives.

Table 4. Inverse quantitative data for criteria "Cost" and "Climate"

\begin{tabular}{lrrrrr}
\hline & Cost & Availability & Climate & Dependency & Utilizability \\
\hline Photovoltaics & $1 / 0.15$ & 1897.7 & $1 / 101$ & 1 & 1 \\
Wind mills & $1 / 0.5$ & 1111.2 & $1 / 24$ & 1 & 1 \\
Coal fired power plants & $1 / 0.8$ & 8750.0 & $1 / 153$ & 0 & 0 \\
Sum & 39.17 & 11758.9 & 0.0524 & 2 & 2 \\
\hline
\end{tabular}

Table 5. Normalized quantitative data

\begin{tabular}{|c|c|c|c|c|c|}
\hline & Cost & Availability & Climate & Dependency & Utilizability \\
\hline Photovoltaics & $6.67 / 39.17=0.17$ & 0.16 & 0.19 & 0.50 & 0.50 \\
\hline Wind mills & 0.51 & 0.09 & 0.79 & 0.50 & 0.50 \\
\hline Coal fired power plants & 0.32 & 0.74 & 0.02 & 0.00 & 0.00 \\
\hline
\end{tabular}

For the alternatives we calculate $w_{i}$ :

$w_{\text {Photovoltaics }}=0.17 \cdot 0.16+0.16 \cdot 0.24+0.19 \cdot 0.31+0.50 \cdot 0.10+0.50 \cdot 0.18=0.266$

$w_{\text {Wind }}=0.51 \cdot 0.16+0.09 \cdot 0.24+0.79 \cdot 0.31+0.50 \cdot 0.10+0.50 \cdot 0.18=0.496$

$w_{\text {Coal }}=0.32 \cdot 0.16+0.74 \cdot 0.24+0.02 \cdot 0.31+0.00 \cdot 0.10+0.00 \cdot 0.18=0.239$

Taking crisp numbers would deliver a clear result. Wind energy is the alternative with by far the highest global weight of 0.50 and would therefore be the most preferable alternative. However, it could be of advantage not only to take the crisp numbers but also the fuzzy numbers (e.g. to better anticipate the uncertainties of future outcomes). In this case, we would again get fuzzy numbers, which could then be taken to estimate possible future intervals, where the "true" weights should lie: 


$$
\begin{aligned}
& w_{\text {Photovoltaics }}=(0.14,0.27,0.52) \\
& w_{\text {Wind }}=(0.25,0.50,0.98) \\
& w_{\text {Coal }}=(0.12,0.24,0.48)
\end{aligned}
$$

A possible interpretation of these fuzzy numbers will follow within the next final section of this article.

\section{Conclusion and outlook}

Up until now, we could show the principal feasibility of fuzzy logic for the purpose of MCDM. If we would have to make one finite choice between the relevant alternatives, we would certainly choose the alternative "windmills". However, decision making does not always imply a choice between alternatives, but could also refer to probabilities, possibilities or considerations concerning opportunities vs. risks.

Consider the following situation: a governmental institution has to decide which alternative energy sources should be promoted in the long run. The fuzzy numbers could then be taken to guarantee the minimum and maximum amount of subsidies for the future development of selected energy sources. We could even take $\alpha$-cuts (Buckley and Eslami, 2002, 46) to define narrower lower and upper limits of the relevant weightings (e.g., the institution could quote a certain $\alpha$-cut based on risk considerations). In Fig. 3 this is visualized for the membership function $\mu(x)=0.8$. In this case we would calculate the following weightings using equation (2):

$$
\begin{aligned}
& 0.24 \leq w_{\text {Photovoltaics }} \leq 0.32 \\
& 0.45 \leq w_{\text {Wind }} \leq 0.59 \\
& 0.21 \leq w_{\text {Coal }} \leq 0.29
\end{aligned}
$$

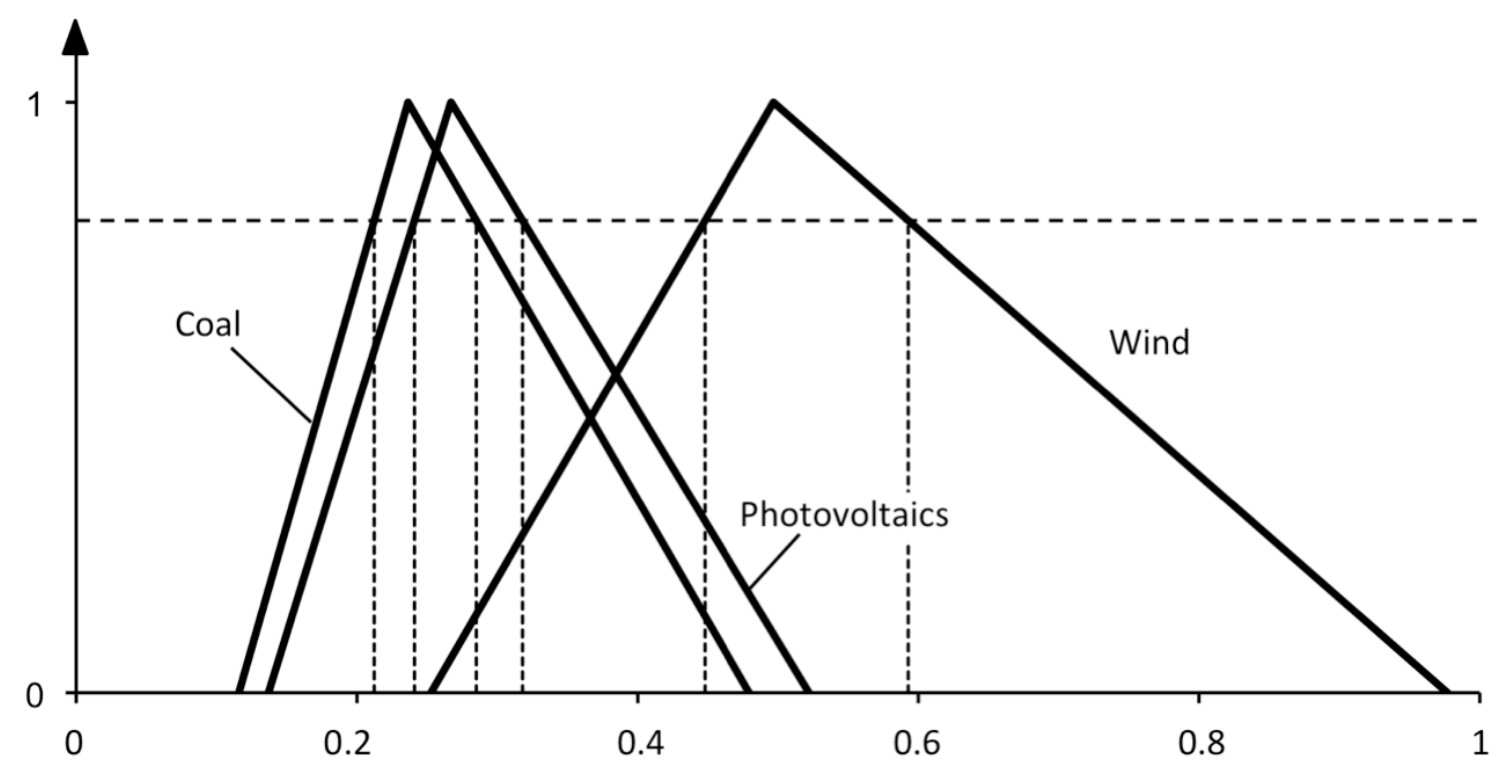

Fig. 3. Fuzzy evaluation of energy sources with $\alpha$-cut $\mu(x)=0.8$

The institution could then guarantee a certain interval of subsidies for the promotion of the evaluated energy sources, depending on future developments. If for example, the total grants should amount to "about" 1 bn Euros (i.e. a fuzzy amount of money), the guaranteed interval of grants could be calculated as in Table 6. The institution could then schedule a prospective budget between 0.9 and 1.2 bn Euros of 
subsidies. This would anticipate future uncertainties much better than compared to a calculation based on crisp weightings.

Table 6 . Interval of subsidies based on fuzzy weightings and $\alpha$-cut $\mu(x)=0.8$

\begin{tabular}{lrrrrrr}
\hline & $w_{l}$ & min. subsidies & $w_{m}$ & $\begin{array}{r}\text { mid-level } \\
\text { subsidies }\end{array}$ & $w_{u}$ & max. subsidies \\
\hline Photovoltaics & 0.24 & 240922239 & 0.27 & 266917037 & 0.32 & 317943545 \\
Windmills & 0.45 & 447919734 & 0.50 & 496738609 & 0.59 & 592785984 \\
Coal fired power plants & 0.21 & 212247917 & 0.24 & 236344354 & 0.28 & 284957911 \\
\hline Total & & 901089891 & & 1000000000 & & 1195687440 \\
\hline
\end{tabular}

This application, a new way of determining future budgets, should visualize the practical benefit of fuzzy logic and MCDM by use of the fuzzy AHP. As mentioned above, it would be necessary to improve the hierarchical structure of the decision problem, as well as the data basis for the evaluation of the alternatives. Furthermore, this approach could also be applied for many other complex decision problems. The topic "energy" served more or less as an adequate empirical field to demonstrate the practical application of theoretical considerations.

We cannot conclude if one specific method of estimating fuzzy priorities is superior to another; both methods used within this study seem to be appropriate provided that consistency can be assured. More research on this topic should follow. As mentioned above, it seems to be advisable to use the geometric mean to aggregate lower and upper limits of fuzzy numbers. It cannot be guaranteed that we will then get satisfying results. However, isolated runaway evaluations will not harm the overall performance of the fuzzy logic based analysis. At large, we could show the practicability and the benefits of the fuzzy AHP for group decisions and show a practical application of this method. The constraints mentioned above should lead to further research activities, for example, to develop adequate grouping algorithms (fuzzy clustering); this would help to analyze large samples of decision makers thoroughly, e.g. by use of the fuzzy distance algorithm of $\mathrm{Xu}$ and Chen $(2007,254)$. By all means, this could further improve the quality of conclusions based on fuzzy AHP in group decisions.

\section{ACKNOWLEDGMENTS}

The author wishes to thank all students of the University of Natural Resources and Applied Life Sciences Vienna taking part in this study as well as his colleagues, especially Christoph Ameseder and Rachael Williams, for their valuable suggestions and help in conducting the study.

\section{REFERENCES}

BMU - Bundesministerium für Umwelt, Naturschutz und Reaktorsicherheit, eds., 2009. Entwicklung der erneuerbaren Energien in Deutschland im Jahr 2008 (AGEE-Stat). BMU-KI III 1 - Daten EE 2008, Stand April 2009.

BMU - Bundesministerium für Umwelt, Naturschutz und Reaktorsicherheit, eds., 2004. Ökologisch optimierter Ausbau der Nutzung erneuerbarer Energien in Deutschland. FKZ 90141 803, Berlin.

BP, 2008. BP Statistical Review of World Energy. June 2008. www.bp.com/statisticalreview.

Buckley, J.J.,1985. Fuzzy hierarchical analysis. Fuzzy Sets and Systems, 34, 187-195. 
Buckley, J.J., \& Eslami, E., 2002. An Introduction to Fuzzy Logic and Fuzzy Sets. Heidelberg, New York, Physika-Verlag.

Buckley, J.J., Feuring, T., \& Hayashi, Y., 2001. Fuzzy hierarchical analysis revisited. European Journal of Operational Research, 129, 48-84.

Büyüközkam, G., \& Feyziog̃lu, O., 2004. A fuzzy-logic-based decision-making approach for new product development. International Journal of Production Economics, 90, 27-45.

Cebeci, U., 2009. Fuzzy AHP-based decision support system for selecting ERP systems in textile industry by using balanced scorecard. Expert Systems with Applications, 36, 8900-8909.

Chang, C.-W., Wu, C.-R., \& Lin, H.-L., 2009. Applying fuzzy hierarchy multiple attributes to construct an expert decision making process. Expert Systems with Applications, 36, 7363-7368.

Chang, D.-Y., 1996. Applications of the extent analysis method on fuzzy AHP. European Journal of Operational Research, 95, 649-655.

Chang, T.-H., \& Wang T.-C., 2009. Using the fuzzy multi-criteria decision making approach for measuring the possibility of successful knowledge management. Information Sciences 179, 355-370.

Chutima, P., \& Suwanfuji, P., 1998. Fuzzy Analytical Hierarchy Process Part Routing in FMS. Thammasat International Journal of Science and Technology, 3(2), 29-47.

Csutora, R., \& Buckley, J.J., 2001. Fuzzy hierarchical analysis: the Lambda-Max method. Fuzzy Sets and Systems, 120, 181-195.

Dağdeviren M., Yavuz, S., \& Kilinç, N., 2009. Weapon selection using the AHP and TOPSIS methods under fuzzy environment. Expert Systems with Applications, 36, 8143-8151.

Dağdeviren M., \& Yüksel, I., 2008. Developing a fuzzy analytic hierarchy process (AHP) model for behavior-based safety management. Information Sciences, 178, 1717-1733.

Davies, M.A.P., 1994. A Multicriteria Decision Model Application for Managing Group Decisions. The Journal of the Operational Research Society, 45(1), 47-58.

Eickemeier, S., \& Rommelfanger, H. 2001. Fuzzy Utility Value Analysis and Fuzzy Analytic Hierarchy Process. Proceedings of the EUROFUSE PM'01, Grenada, April 25-27, 139-146.

Garciá, J.L., De la Plaza, S., Navas, L.M., Benavente, M., \& Luna, L., 1998. Evaluation of the Feasibility of Alternative Energy Sources for Greenhouse Heating. Journal of agricultural Engineering Resources, 69, 107-114.

Georgilakis, P.S., \& Katsigiannes, Y.A., 2009. Reliability and economic evaluation of small autonomous power systems containing only renewable energy sources. Renewable Energy, 34, 65-70.

Güngör, Z., Serhadlioğlu, G., \& Kesen, E., 2009. A fuzzy AHP approach to personnel selection problem. Applied Soft Computing, 9, 641-646.

Jaber, J.O., Jaber, Q.M., Sawalha, S.A., \& Mohsen, M.S., 2008. Evaluation of conventional and renewable energy sources for space heating in the household sector. Renewable and Sustainable Energy Reviews, 12, 278-289. 
Ji, P., \& Jiang, R., 2003. Scale Transitivity in the AHP. The Journal of the Operational Research Society, 54(8), 896-905.

Kong, F., \& Liu, H., 2005. Applying fuzzy analytic hierarchy process to evaluate success factors of ecommerce. International Journal of Information and Systems sciences, 1(3-4), 406-412.

Mikhailov, L., 2003. Deriving priorities from fuzzy pairwise comparison judgements. Fuzzy Sets and Systems, 134, 365-385.

Mikhailov, L., 2004. A fuzzy approach to deriving priorities from interval pairwise comparison judgements. European Journal of Operational Research, 159, 687-704.

Opricovic, S., \& Tzeng, G.-H., 2003. Defuzzification within a multicriteria decision model. International Journal of Uncertainty, Fuzziness and Knowledge-Based Systems, 11(5), 635-652.

Seçme, N.Y., Bayarakdog̃lu, A., \& Kahraman, C. (2009). Fuzzy performance evaluation in Turkish Banking Sector using Analytic Hierarchy Process and TOPSIS. Expert Systems with Applications (article in press).

Saaty, T.L., 1980. The Analytic Hierarchy Process. McGraw-Hill International, New York.

Saaty, T.L., 1995. Decision Making for Leaders. The Analytic Hierarchy Process for Decisions in a Complex World. 1995/1996 ed., completely revised. RWS Publications, Pittsburgh.

Saaty, T.L., 2006. Fundamentals of Decision Making and Prioritiy Theory with the Analytic Hierarchy Process. Vol. VI of the AHP Series. Sec. Ed., sec. printing, RWS Publications, Pittsburgh.

Sredjevic, B., \& Medeiros, Y.D.P., 2008. Fuzzy AHP Assessment of Water Management Plans. Water Resources Management, 22, 877-894.

Stieler, W., 2006. Bis zum letzten Tropfen. Serie die Zukunft der Energie. Technology Report, 11, 48-54.

WWEA - World Wind Energy Associagtion, 2009. World Wind Energy Report 2008. WWEA, Bonn, Germany.

Xu, Z.-S., \& Chen, J, 2007. An interactive method for fuzzy multiple attribute group decision making. Information Sciences, 177, 248-263.

Zadeh, L.A., 1965. Fuzzy Sets. Information and Control, 8, 338-353. 